\title{
Thyroid Dysfunction and Associated Risk Factors among Nepalese Diabetes Mellitus Patients
}

\author{
Saroj Khatiwada, ${ }^{1}$ Rajendra KC, ${ }^{2}$ Santosh Kumar Sah, ${ }^{3}$ Seraj Ahmed Khan, \\ Rajendra Kumar Chaudhari, ${ }^{4}$ Nirmal Baral, ${ }^{4}$ and Madhab Lamsal ${ }^{4}$ \\ ${ }^{1}$ Department of Pharmacy, Central Institute of Science and Technology (CIST) College, Pokhara University, Kathmandu, Nepal \\ ${ }^{2}$ Department of Medical Laboratory Technology, Modern Technical College, Satdobato, Lalitpur, Nepal \\ ${ }^{3}$ Department of Biochemistry, Universal College of Medical Sciences, Bhairahawa, Nepal \\ ${ }^{4}$ Department of Biochemistry, B. P. Koirala Institute of Health Sciences, Dharan, Nepal
}

Correspondence should be addressed to Saroj Khatiwada; khatiwadasaroj22@gmail.com

Received 15 May 2015; Revised 15 July 2015; Accepted 28 July 2015

Academic Editor: Carlo Cappelli

Copyright (C) 2015 Saroj Khatiwada et al. This is an open access article distributed under the Creative Commons Attribution License, which permits unrestricted use, distribution, and reproduction in any medium, provided the original work is properly cited.

\begin{abstract}
Objectives. To assess thyroid function and associated risk factors in Nepalese diabetes mellitus patients. Methods. A cross-sectional study was carried out among 419 diabetes mellitus patients at B. P. Koirala Institute of Health Sciences, Dharan, Nepal. Information on demographic and anthropometric variables and risk factors for thyroid dysfunction was collected. Blood samples were analysed to measure thyroid hormones, blood sugar, and lipid profile. Results. Prevalence rate of thyroid dysfunction was $36.03 \%$, with subclinical hypothyroidism $(26.5 \%)$ as the most common thyroid dysfunction. Thyroid dysfunction was much common in females (42.85\%) compared to males $(30.04 \%)(p=0.008)$ and in type 1 diabetes $(50 \%)$ compared to type 2 diabetes mellitus $(35.41 \%)$ $(p=0.218)$. Diabetic patients with thyroid dysfunction had higher total cholesterol, HDL cholesterol, and LDL cholesterol in comparison to patients without thyroid dysfunction. Significant risk factors for thyroid dysfunction, specifically hypothyroidism (overt and subclinical), were smoking (relative risk of 2.56 with 95\% CI (1.99-3.29, $p<0.001$ )), family history of thyroid disease (relative risk of 2.57 with 95\% CI $(2.0-3.31, p<0.001)$ ), and female gender (relative risk of 1.44 with 95\% CI $(1.09-1.91, p=0.01)$ ). Conclusions. Thyroid dysfunction is common among Nepalese diabetic patients. Smoking, family history of thyroid disease, and female gender are significantly associated with thyroid dysfunction.
\end{abstract}

\section{Introduction}

Diabetes mellitus is being one of the greatest health threats for the 21st century [1]. Prevalence of diabetes is rising rapidly in developing countries, and the global number of diabetes is estimated to reach 366 million in 2030 among adults aged $\geq 20$ years $[1,2]$. Both type 1 and type 2 diabetes are powerful and independent risk factors for coronary artery disease (CAD), stroke, and peripheral arterial disease [3]. The global rise in diabetes burden has led to significant increase in health care expenditure [2].

There is a deep underlying relation between diabetes mellitus and thyroid dysfunction [4]. Studies have found that thyroid dysfunction is much common in diabetic population compared to nondiabetic population, and diabetes and thyroid disorders have been shown to mutually influence each other [5, 6]. Most often thyroid dysfunction and type 1 diabetes are due to an autoimmune condition, whereas type 2 diabetes is mainly due to insulin resistance $[7,8]$. Thus, it seems that diabetes, especially type 1 , has potential link with thyroid dysfunction or vice versa. Besides the effects due to high blood glucose in diabetics, low thyroid hormones independently increase the risk for cardiovascular diseases in both diabetic and nondiabetic patients [3,9].

Latest reports suggest that diabetes is rising rapidly particularly in developing countries from Asia [2]. A study in eastern Nepal reported diabetes in $6.3 \%$ population [10]. Hence, assessment of thyroid function in the uprising diabetic patient number may be helpful in identifying cases of clinical and subclinical thyroid dysfunction thereby assisting in mitigating the harmful effects due to low thyroid hormones. Thyroid profile in Nepalese population with diabetes 
mellitus has not been studied earlier. Thus, we designed a study by selecting confirmed diabetic patients from eastern Nepal and performed clinical and laboratory evaluation to investigate thyroid function status and associated risk factors.

\section{Materials and Methods}

A cross-sectional study was carried out among the diabetes mellitus patients attending biochemistry laboratory of B. P. Koirala Institute of Health Sciences, Dharan, Nepal, from February 2013 to January 2014. A total of 419 patients with diabetes mellitus were selected during the study period based on our inclusion criteria of having diabetes for at least 6 months. Those diabetic patients with known thyroid disorders, complications of diabetes mellitus, history of other illnesses, and hyperlipidemia as well as on corticosteroids therapy and on medications affecting thyroid function were excluded from the study. Diabetes mellitus was diagnosed on the basis of American Diabetes Association (ADA) criteria and classification of type 1 diabetes from type 2 diabetes was done on basis of physician classifications based on the age of onset of diabetes and dependence on insulin therapy alone to achieve normal plasma glucose concentrations [8]. Consent was taken from each patient and the study protocol was approved by the institute review board of B. P. Koirala Institute of Health Sciences, Dharan.

Each subject demographic (age, sex) and anthropometric measurements (height, weight, and BMI) including blood pressure (systolic and diastolic), duration of diabetes, family history of diabetes mellitus and thyroid disease, and alcohol intake habit and smoking habit was recorded. About $5 \mathrm{~mL}$ overnight fasting venous blood samples were collected at morning time from each patient. Blood glucose, glycated hemoglobin (HbAlc), total cholesterol, high density lipoprotein (HDL) cholesterol, low density lipoprotein (LDL) cholesterol, triglyceride, free triiodothyronine (T3), free tetraiodothyronine (T4), and thyroid stimulating hormone (TSH) were estimated. Blood glucose and HbAlc were estimated using enzymatic method and by Nycocard reader II based on immunochromatographic principle, respectively. Serum free T3, free T4, and TSH were measured by using fluorescent immunoassay (VIDAS, biomeriux SA, France). Similarly, total cholesterol and triglycerides were measured by enzymatic method (kits from AGAPPE diagnostics by Biolyzer 100). LDL cholesterol and HDL cholesterol were estimated by homogeneous, direct method (kits from Gesan by Biolyzer 100).

Thyroid dysfunction was said to occur if patients thyroid hormones fall outside the reference range (free T3 (4.0$8.3 \mathrm{pmol} / \mathrm{L})$, free T4 (9.0-20.0 pmol/L), and TSH level (0.25$5 \mathrm{mIU} / \mathrm{L})$ ). The data generated from study was entered into MS excel and analyzed using SPSS version 11.0. Continuous variables were expressed as mean $\pm \mathrm{SD}$ values and categorical variables were expressed as percentage (number). One-way ANOVA test was applied for continuous variables and chi square test was applied for categorical variables at 95\% confidence interval. Relative risk with 95\% confidence interval (CI) was used to assess various risk factors for thyroid dysfunction.

\section{Results}

The study population comprised $53.22 \%$ males and $46.77 \%$ females with mean age of $51.27 \pm 15.33$ years. The mean age of males and females was $50.93 \pm 15.44$ years and $51.66 \pm$ 15.24 years, respectively. Type 1 and type 2 diabetes mellitus patients were $4.3 \%(n=18)$ with mean age of $19.28 \pm 1.07$ years and $95.7 \%(n=401)$ with mean age of $52.7 \pm 14.05$ years, respectively. The BMI among type 1 and type 2 diabetics was significantly different $\left(22.64 \pm 1.58 \mathrm{Kg} / \mathrm{m}^{2}\right.$ versus $25.28 \pm$ $\left.2.81 \mathrm{Kg} / \mathrm{m}^{2}, p<0.001\right)$.

Euthyroidism, subclinical hypothyroidism, overt hypothyroidism, and subclinical hyperthyroidism among study population were $64 \%(n=268), 26.5 \%(n=111), 5.5 \%$ $(n=23)$ and $4.1 \%(n=17)$, respectively. Significant difference in thyroid function status was observed among genders $(p=0.024)$. Significantly higher number of diabetic patients without thyroid dysfunction ( $n=39,9.3 \%)$ had hypertension history compared to those with hypothyroidism (both overt and subclinical $)(n=33,7.87 \%)$ and subclinical hyperthyroidism $(n=3,0.71 \%)(p=0.046)$. Parameters of lipid profile were not significantly different among diabetic patients with thyroid dysfunction (overt and subclinical hypothyroidism and subclinical hyperthyroidism) and without thyroid dysfunction (euthyroidism). Free T3 $(p<0.001)$, free T4 $(p<0.001)$, and TSH $(p<0.001)$ were significantly different among diabetic patients with and without thyroid dysfunction. Demographic, anthropometric, and clinical parameters in the study population according to thyroid status, hypothyroidism (both overt and subclinical), subclinical hyperthyroidism, and euthyroidism are shown in Table 1. Similarly, the level of different biochemical parameters in the study population according to thyroid function status is shown in Table 2.

Diabetic males had significantly higher BMI $(25.66 \pm$ $2.8 \mathrm{Kg} / \mathrm{m}^{2}$ versus $24.59 \pm 2.73 \mathrm{Kg} / \mathrm{m}^{2}, p<0.001$ ), systolic blood pressure $(121.84 \pm 7.14 \mathrm{mmHg}$ versus $119.72 \pm$ $6.45 \mathrm{mmHg}, p=0.001)$, and fasting blood glucose (179.99 $\pm 54.72 \mathrm{mg} / \mathrm{dL}$ versus $172.5 \pm 60.44 \mathrm{mg} / \mathrm{dL}, p=0.005)$ than diabetic females, respectively. However, diabetic females had significantly higher HDL cholesterol $(41.2 \pm 4.17 \mathrm{mg} / \mathrm{dL}$ versus $39.46 \pm 2.78 \mathrm{mg} / \mathrm{dL}, p<0.001)$ and triglycerides $(191.38 \pm 105.82 \mathrm{mg} / \mathrm{dL}$ versus $172.32 \pm 101.02 \mathrm{mg} / \mathrm{dL}, p=$ $0.024)$ than diabetic males. Diabetic males and females had no significant difference in diastolic blood pressure (81.41 \pm $5.66 \mathrm{mmHg}$ versus $80.45 \pm 6.26 \mathrm{mmHg}, p=0.124)$, HbAlc $(7.23 \pm 1.99 \%$ versus $7.19 \pm 1.75 \%, p=0.411)$, total cholesterol $(188.44 \pm 54.91 \mathrm{mg} / \mathrm{dL}$ versus $192.44 \pm 50.97 \mathrm{mg} / \mathrm{dL}, p=$ $0.187)$, LDL cholesterol $(112.11 \pm 47.61 \mathrm{mg} / \mathrm{dL}$ versus 110.77 $\pm 41.72 \mathrm{mg} / \mathrm{dL}, p=0.704)$, free $\mathrm{T} 3(5.03 \pm 1.21 \mathrm{pmol} / \mathrm{L}$ versus $5.04 \pm 1.39 \mathrm{pmol} / \mathrm{L}, p=0.587)$, free $\mathrm{T} 4(11.78 \pm$ $3.46 \mathrm{pmol} / \mathrm{L}$ versus $11.78 \pm 3.61 \mathrm{pmol} / \mathrm{L}, p=0.914)$, and TSH $(4.02 \pm 3.27 \mathrm{mIU} / \mathrm{L}$ versus $5.29 \pm 5.03 \mathrm{mIU} / \mathrm{L}, p=0.135)$, respectively.

Thyroid dysfunction was more common in type 1 diabetic patients $(50 \%, n=9)$ as compared to type 2 diabetic patients $(35.41 \%, n=142)$ and in diabetic females $(42.85 \%, n=84)$ than in diabetic males $(30.04 \%, n=67)$. Hypothyroidism was the only thyroid dysfunction in type 1 diabetes patients, 
TABLE 1: General characteristics of the study population.

\begin{tabular}{|c|c|c|c|c|c|}
\hline \multirow[b]{2}{*}{ Variables } & \multirow{2}{*}{ All patients $(n=419)$} & \multicolumn{2}{|c|}{ Diabetic patients with thyroid dysfunction $(n=151)$} & \multirow{2}{*}{$\begin{array}{l}\text { Diabetic patients } \\
\text { without thyroid } \\
\text { dysfunction } \\
(n=268)\end{array}$} & \multirow[b]{2}{*}{$p$ value } \\
\hline & & $\begin{array}{l}\text { Hypothyroidism* } \\
\quad(n=134)\end{array}$ & $\begin{array}{l}\text { Subclinical } \\
\text { hyperthyroidism } \\
\quad(n=17)\end{array}$ & & \\
\hline \multicolumn{6}{|l|}{ Gender } \\
\hline Male & $53.22 \%(n=223)$ & $14.08 \%(n=59)$ & $1.9 \%(n=8)$ & $37.23 \%(n=156)$ & \multirow{2}{*}{0.024} \\
\hline Female & $46.77 \%(n=196)$ & $17.89 \%(n=75)$ & $2.14 \%(n=9)$ & $26.73 \%(n=112)$ & \\
\hline Age (years) & $51.27 \pm 15.33$ & $48.72 \pm 17.58$ & $54.47 \pm 12.3$ & $52.35 \pm 14.14$ & 0.055 \\
\hline \multicolumn{6}{|l|}{ Diabetes type } \\
\hline Type 1 DM & $4.3 \%(n=18)$ & $2.14 \%(n=9)$ & - & $2.14 \%(n=9)$ & \multirow{2}{*}{0.197} \\
\hline Type 2 DM & $95.7 \%(n=401)$ & $29.83 \%(n=125)$ & $4.05 \%(n=17)$ & $61.81 \%(n=259)$ & \\
\hline Diabetes duration (years) & $3.77 \pm 2.63$ & $4.04 \pm 3.1$ & $3.77 \pm 2.97$ & $3.64 \pm 2.33$ & 0.354 \\
\hline Hypertension & $17.9 \%(n=75)$ & $7.87 \%(n=33)$ & $0.71 \%(n=3)$ & $9.3 \%(n=39)$ & 0.046 \\
\hline Smoking habit & $19.3 \%(n=81)$ & $12.17 \%(n=51)$ & $0.71 \%(n=3)$ & $6.44 \%(n=27)$ & $<0.001$ \\
\hline Alcoholism & $31.5 \%(n=132)$ & $10.5 \%(n=44)$ & $0.95 \%(n=4)$ & $20.04 \%(n=84)$ & 0.736 \\
\hline Family history of diabetes mellitus & $32.9 \%(n=138)$ & $10.73 \%(n=45)$ & $2.14 \%(n=9)$ & $20.04 \%(n=84)$ & 0.181 \\
\hline Family history of thyroid disease & $20.8 \%(n=87)$ & $12.88 \%(n=54)$ & $0.71 \%(n=3)$ & $7.15 \%(n=30)$ & $<0.001$ \\
\hline $\operatorname{BMI}\left(\mathrm{Kg} / \mathrm{m}^{2}\right)$ & $25.16 \pm 2.82$ & $24.98 \pm 2.67$ & $25.5 \pm 2.62$ & $25.23 \pm 2.9$ & 0.623 \\
\hline Systolic blood pressure (mmHg) & $120.85 \pm 6.9$ & $121.37 \pm 7.12$ & $119.94 \pm 6.3$ & $120.65 \pm 6.82$ & 0.523 \\
\hline Diastolic blood pressure $(\mathrm{mmHg})$ & $80.96 \pm 5.96$ & $81.43 \pm 6.19$ & $80.24 \pm 5.1$ & $80.78 \pm 5.9$ & 0.52 \\
\hline
\end{tabular}

The data is presented as percentage (number) and as mean \pm SD. $p$ value was calculated among diabetic subjects with hypothyroidism and hyperthyroidism and without thyroid dysfunction at $95 \%$ confidence interval. ${ }^{*}$ Hypothyroidism group included both subclinical and overt hypothyroids.

TABLE 2: Biochemical parameters in the study population.

\begin{tabular}{|c|c|c|c|c|c|}
\hline \multirow[b]{2}{*}{ Variables } & \multirow[b]{2}{*}{ All patients $(n=419)$} & \multicolumn{2}{|c|}{ Diabetic patients with thyroid dysfunction $(n=151)$} & \multirow{2}{*}{$\begin{array}{l}\text { Diabetic patients } \\
\text { without thyroid } \\
\text { dysfunction } \\
(n=268)\end{array}$} & \multirow[b]{2}{*}{$p$ value } \\
\hline & & $\begin{array}{l}\text { Hypothyroidism* } \\
\quad(n=134)\end{array}$ & $\begin{array}{c}\text { Subclinical } \\
\text { hyperthyroidism } \\
(n=17)\end{array}$ & & \\
\hline Fasting blood glucose (mg/dL) & $176.48 \pm 57.53$ & $174.13 \pm 51.99$ & $165.59 \pm 53.25$ & $178.35 \pm 60.42$ & 0.574 \\
\hline $\mathrm{HbAlc} \%$ & $7.21 \pm 1.88$ & $7.5 \pm 2.13$ & $6.73 \pm 1.18$ & $7.1 \pm 1.77$ & 0.076 \\
\hline Total cholesterol (mg/dL) & $190.31 \pm 53.08$ & $191.05 \pm 54.14$ & $198.58 \pm 46.13$ & $189.41 \pm 53.08$ & 0.774 \\
\hline HDL cholesterol (mg/dL) & $40.27 \pm 3.6$ & $40.72 \pm 3.73$ & $40.29 \pm 3.01$ & $40.05 \pm 3.56$ & 0.209 \\
\hline LDL cholesterol (mg/dL) & $111.48 \pm 44.9$ & $112.09 \pm 45.22$ & $115.1 \pm 45.21$ & $110.95 \pm 44.88$ & 0.917 \\
\hline Triglycerides (mg/dL) & $181.24 \pm 103.61$ & $178.72 \pm 111.22$ & $198.18 \pm 99.52$ & $181.42 \pm 100.14$ & 0.766 \\
\hline Free T3 $(\mathrm{pmol} / \mathrm{L})$ & $5.03 \pm 1.3$ & $4.65 \pm 1.21$ & $5.63 \pm 1.07$ & $5.19 \pm 1.31$ & $<0.001$ \\
\hline Free T4 (pmol/L) & $11.78 \pm 3.52$ & $10.45 \pm 2.54$ & $13.75 \pm 3.48$ & $12.31 \pm 3.75$ & $<0.001$ \\
\hline TSH (mIU/L) & $4.62 \pm 4.23$ & $9.45 \pm 4.31$ & $0.18 \pm 0.041$ & $2.48 \pm 1.12$ & $<0.001$ \\
\hline
\end{tabular}

The data is presented as mean \pm SD. $p$ value was calculated among diabetic subjects with hypothyroidism and hyperthyroidism and without thyroid dysfunction at $95 \%$ confidence interval. * Hypothyroidism group included both subclinical and overt hypothyroids.

whereas it was the major thyroid dysfunction in type 2 diabetes patients $(31.17 \%, n=125)$. Significant risk factors for thyroid dysfunction were smoking (relative risk 2.32 with 95\% CI (1.85-2.91, $p<0.001)$ ), family history of thyroid disease (relative risk 2.31 with $95 \%$ CI $(1.84-2.91, p<0.001)$ ), and female gender (relative risk 1.42 with 95\% CI (1.1-1.84, $p=0.006)$ ). When separately analyzed, significant risk factors for hypothyroidism included smoking (relative risk of 2.56 with $95 \%$ CI $(1.99-3.29, p<0.001)$ ), family history of thyroid disease (relative risk of 2.57 with $95 \%$ CI (2.0-3.31, $p<0.001)$ ), and female gender (relative risk of 1.44 with 95\% CI (1.09-1.91, $p=0.01)$ ). However, smoking, family history of thyroid disease, and female gender did not appear as significant risk factors for subclinical hyperthyroidism. Age $\geq 60$ years and duration of diabetes $\geq 5$ years had relative risk of 1.03 with $95 \% \mathrm{CI}(0.79-1.35, p=0.79)$ and 1.3 with $95 \%$ CI $(1.0-1.68, p=0.053)$, respectively, for thyroid dysfunction.

\section{Discussion}

Diabetic patients have susceptibility to different types of thyroid dysfunction, whether hypothyroidism or hyperthyroidism; at the same time, patients with thyroid dysfunction 
are susceptible to suffer from either type 1 diabetes or type 2 diabetes [5]. The present study finds thyroid dysfunction as a common endocrine disorder in diabetic patients, where we reported that $36.03 \%$ diabetic patients had thyroid dysfunction. Studies have reported high prevalence of thyroid dysfunction in Nepal even in the general population. A hospital based study by Baral et al. in eastern Nepal reported hypothyroidism and hyperthyroidism in $17.19 \%$ and $13.68 \%$ population, respectively [11]. Similarly, in a study in Kavre district of central Nepal, thyroid dysfunction was observed in $31.84 \%$ metabolic syndrome patients [12]. While iodine nutrition has been rapidly improving in the past years in Nepal, excess iodine intake, as indicated by recent studies in school children of eastern Nepal, could also be a responsible factor for the high prevalence of thyroid dysfunction specifically hypothyroidism in our study population. Both iodine excess and deficiency have been found to affect thyroid gland function [13]. The most common thyroid dysfunction in the present study was subclinical hypothyroidism $(26.5 \%)$ followed by overt hypothyroidism (5.5\%) and subclinical hyperthyroidism $(4.1 \%)$. We reported higher prevalence of thyroid dysfunction in females $(42.85 \%)$ than in males (30.04\%), which has been well observed in many studies. Our results are in agreement with previous studies in India, Saudi Arabia, and Greece $[5,14,15]$. A retrospective study in India reported thyroid dysfunction in $31.2 \%$ of type 2 diabetic patients with $27.7 \%$ having hypothyroidism [14]. Similarly, a study in Saudi Arabia found thyroid dysfunction in $28.5 \%$ of type 2 diabetic patients, with $25.3 \%$ having hypothyroidism [5]. Prevalence of thyroid dysfunction was much lower than in our study among the type 2 diabetic patients of Greece where thyroid dysfunction prevalence was $12.3 \%$ (5.53\% in males and $18.48 \%$ in females) [15].

We observed that thyroid dysfunction is more common in type 1 diabetic patients (50\%) than in type 2 diabetic patients (35.41\%). Various studies have revealed that autoimmune thyroid disease is the commonest autoimmune disorder associated with type 1 diabetes. Type 1 diabetes and autoimmune thyroid disease share an autoimmune disposition, and recent studies have shown a shared genetic susceptibility to both conditions [16]. Kordonouri et al. also found thyroid dysfunction to be more common in subjects with type 1 diabetes compared to those with type 2 diabetes and a 3.5fold increased risk of autoimmune thyroiditis was noticed in GADA positive patients [17].

Thyroid hormones have prominent roles in regulating a number of metabolic pathways including lipoprotein metabolism [9]. We found that diabetic patients with thyroid disorders, hypothyroidism, or subclinical hyperthyroidism had higher total cholesterol and LDL cholesterol than those without thyroid dysfunction. Dyslipidemia is a reported complication of hypothyroidism in patients with or without diabetes. However, in the study in Greece, patients with thyroid dysfunction had higher HDL cholesterol levels and lower values of LDL cholesterol levels in comparison with patients without thyroid dysfunction [15].

The present study reveals that hypertension (17.9\%), smoking habit (19.3\%), alcohol intake (31.5\%), family history of diabetes mellitus (32.9\%), and family history of thyroid disease $(20.8 \%)$ are common among Nepalese patients with diabetes. Among the various risk factors for thyroid dysfunction we studied, smoking, family history of thyroid disease, and female gender had significant risk for thyroid dysfunction, specifically hypothyroidism. Similar result was observed by Papazafiropoulou et al., who reported that presence of thyroid dysfunction was related with gender and LDL cholesterol levels in type 2 diabetic patients [15]. Similarly, AlGeffari et al. found family history of thyroid disease, female gender, and duration of diabetes of $>10$ years as significant risk factor for thyroid dysfunction in type 2 diabetic patients [5]. In a study by Chubb et al. subclinical hypothyroidism was associated with anti-TPO status and age, but there were no independent associations with serum cholesterol, history of coronary heart disease, HbAlc, or hypoglycaemic therapy in diabetic women [18].

Thyroid disorders and diabetes mellitus have a complex interdependent interaction. In diabetic patients, the nocturnal TSH peak is blunted or abolished, and the TSH response to TRH is impaired. Reduced T3 levels have been observed in uncontrolled diabetic patients, which is due to impairment in peripheral conversion of $\mathrm{T} 4$ to $\mathrm{T} 3$ that normalizes with improvement in glycemic control. Higher levels of circulating insulin associated with insulin resistance have shown a proliferative effect on thyroid tissue resulting in larger thyroid size with increased formation of nodules [6]. Diabetic patients have strong chance of developing thyroid dysfunction over the time course. A study by Chubb et al., in women with type 2 diabetes without known thyroid disease at baseline, revealed that diabetic women develop subclinical hypothyroidism $(8.6 \%)$ over time as found after 5 years [18]. Furthermore, it seems that unidentified thyroid dysfunction could negatively impact diabetes and its complications. A higher frequency of retinopathy and nephropathy was observed in diabetic patients with subclinical hypothyroidism, and more severe retinopathy was noted as well. Therefore, management of subclinical hypothyroidism in patients with diabetes may prove highly beneficial [6].

Thyroid function test is not a commonly recommended investigation in patients with diabetes especially in undeveloped countries like Nepal. Based on our findings and the reported harmful effects of low thyroid hormones on cardiovascular health, we recommend the frequent screening (1-2 years) of thyroid function in patients with diabetes. Our findings provide an evidence for the importance and necessity of thyroid function screening in patients with diabetes. This will assist in better clinical management of diabetes patients. The present study has however few limitations. The prevalence of anti-TPO antibodies in the study population could not be assessed. Assessment of anti-TPO antibodies would have provided clues for the thyroid autoimmunity status in the study population, which could have helped to explain the high rate of thyroid dysfunction. Autoimmunity against the thyroid gland is one of the most important causes for thyroid dysfunction. Anti-TPO antibody estimation helps in establishing the etiological diagnosis of autoimmune thyroid diseases. Anti-TPO antibodies are the most prevalent and present in $80-90 \%$ of Hashimoto's thyroiditis, $65-75 \%$ of grave's disease, and 10-20\% of nodular goiter or thyroid 
carcinoma [19]. Another limitation of the present study was that thyroid function was tested only once, which may have resulted in the inclusion of subjects with nonthyroidal illness. The other limitation of the present study was that the iodine status of the study population was not assessed. Iodine excess and deficiency both are found to be associated with thyroid dysfunction and thus the concurrent prevalence of such iodine nutrition conditions in the study population may have some contributions to the high prevalence of thyroid dysfunction [20].

In conclusion, the present study identifies thyroid dysfunction, as well as prominently subclinical hypothyroidism, as a common disorder in Nepalese patients with diabetes. Diabetic patients with thyroid dysfunction had higher lipid levels (total cholesterol and LDL cholesterol) than patients without thyroid dysfunction, so diabetic patients with thyroid dysfunction are at higher risk for cardiovascular diseases than those with normal thyroid function. Similarly, smoking, family history of thyroid disease, and female gender were associated with thyroid dysfunction (mainly hypothyroidism) in the study population. Thus, frequent screening for thyroid dysfunction especially in diabetic patients with family history of thyroid disease, female gender, and smoking habit needs to be done.

\section{Conflict of Interests}

The authors declare that there is no conflict of interests regarding the publication of this paper.

\section{Authors' Contribution}

Saroj Khatiwada designed the study, performed laboratory and statistical analysis, and wrote the paper. Rajendra KC, Santosh Kumar Sah, Seraj Ahmed Khan, Rajendra Kumar Chaudhari, Nirmal Baral, and Madhab Lamsal helped in study design and paper draft and review. All authors read and approved the final version of the paper.

\section{Acknowledgment}

The authors kindly acknowledge B. P. Koirala Institute of Health Sciences for providing resources for the study. This study was done at the Department of Biochemistry of B. P. Koirala Institute of Health Sciences (BPKIHS), Dharan, Nepal.

\section{References}

[1] D. Soumya and B. Srilatha, "Late stage complications of diabetes and insulin resistance," Journal of Diabetes and Metabolism, vol. 2, no. 167, Article ID 1000167, 7 pages, 2011.

[2] M.-Z. Li, L. Su, B.-Y. Liang et al., "Trends in prevalence, awareness, treatment, and control of diabetes mellitus in mainland China from 1979 to 2012," International Journal of Endocrinology, vol. 2013, Article ID 753150, 14 pages, 2013.

[3] D. Aronson, "Hyperglycemia and the pathobiology of diabetic complications," Advances in Cardiology, vol. 45, pp. 1-16, 2008.
[4] C. Wang, "The relationship between type 2 diabetes mellitus and related thyroid diseases," Journal of Diabetes Research, vol. 2013, Article ID 390534, 9 pages, 2013.

[5] M. Al-Geffari, N. A. Ahmad, A. H. Al-Sharqawi, A. M. Youssef, D. Alnaqeb, and K. Al-Rubeaan, "Risk factors for thyroid dysfunction among type 2 diabetic patients in a highly diabetes mellitus prevalent society," International Journal of Endocrinology, vol. 2013, Article ID 417920, 6 pages, 2013.

[6] M. Hage, M. S. Zantout, and S. T. Azar, "Thyroid disorders and diabetes mellitus," Journal of Thyroid Research, vol. 2011, Article ID 439463, 7 pages, 2011.

[7] M. Helfand and L. M. Crapo, "Screening for thyroid disease," Annals of Internal Medicine, vol. 112, no. 11, pp. 840-849, 1990.

[8] American Diabetes Association, "Classification and diagnosis of diabetes. Sec. 2. In Standards of Medical Care in Diabetes 2015," Diabetes Care, vol. 38, no. 1, pp. S8-S16, 2015.

[9] L. J. N. Van Tienhoven-Wind and R. P. F. Dullaart, "Low-normal thyroid function and novel cardiometabolic biomarkers," Nutrients, vol. 7, no. 2, pp. 1352-1377, 2015.

[10] S. K. Sharma, A. Ghimire, J. Radhakrishnan et al., "Prevalence of hypertension, obesity, diabetes, and metabolic syndrome in Nepal," International Journal of Hypertension, vol. 2011, Article ID 821971, 9 pages, 2011.

[11] N. Baral, M. Lamsal, B. C. Koner, and S. Koirala, "Thyroid dysfunction in Eastern Nepal," Southeast Asian Journal of Tropical Medicine and Public Health, vol. 33, no. 3, pp. 638-641, 2002.

[12] P. Gyawali, J. S. Takanche, R. K. Shrestha et al., "Pattern of thyroid dysfunction in patients with metabolic syndrome and its relationship with components of metabolic syndrome," Diabetes and Metabolism Journal, vol. 39, no. 1, pp. 66-73, 2015.

[13] S. Khatiwada, B. Gelal, P. R. Shakya, M. Lamsal, and N. Baral, "Urinary iodine excretion among Nepalese school children in Terai region," The Indian Journal of Pediatrics, 2015.

[14] L. Demitrost and S. Ranabir, "Thyroid dysfunction in type 2 diabetes mellitus: a retrospective study," Indian Journal of Endocrinology and Metabolism, vol. 16, pp. S334-S335, 2012.

[15] A. Papazafiropoulou, A. Sotiropoulos, A. Kokolaki, M. Kardara, P. Stamataki, and S. Pappas, "Prevalence of thyroid dysfunction among Greek type 2 diabetic patients attending an outpatient clinic," Journal of Clinical and Medical Research, vol. 2, no. 2, pp. 75-78, 2010.

[16] B. I. Joffe and L. A. Distiller, "Diabetes mellitus and hypothyroidism: strange bedfellows or mutual companions?" World Journal of Diabetes, vol. 5, no. 6, pp. 901-904, 2014.

[17] O. Kordonouri, N. Charpentier, and R. Hartmann, "GADA positivity at onset of type 1 diabetes is a risk factor for the development of autoimmune thyroiditis," Pediatric Diabetes, vol. 12, no. 1, pp. 31-33, 2011.

[18] S. A. P. Chubb, W. A. Davist, Z. Inman, and T. M. E. Davis, "Prevalence and progression of subclinical hypothyroidism in women with type 2 diabetes: the Fremantle Diabetes Study," Clinical Endocrinology, vol. 62, no. 4, pp. 480-486, 2005.

[19] E. Jeena, M. Malathi, and K. Sudeep, "A hospital-based study of anti-TPO titer in patients with thyroid disease," Muller Journal of Medical Sciences and Research, vol. 4, no. 2, pp. 74-77, 2013.

[20] S. Khatiwada, B. Gelal, M. K. Tamang et al., "Iodized salt use and salt iodine content among household salts from six districts of eastern Nepal," Journal of Nepal Health Research Council, vol.12, no. 18, pp. 191-194, 2014. 


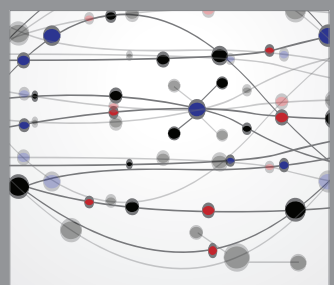

The Scientific World Journal
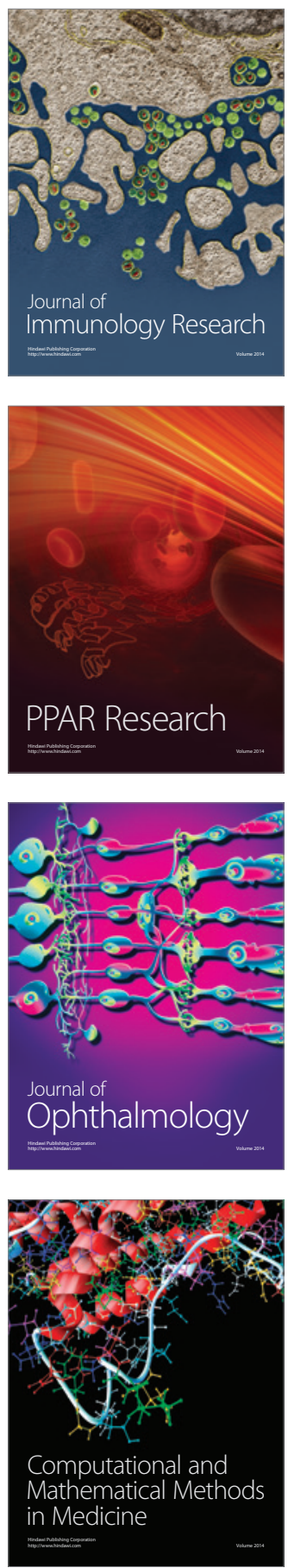

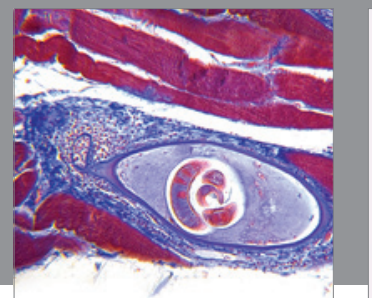

Gastroenterology

Research and Practice
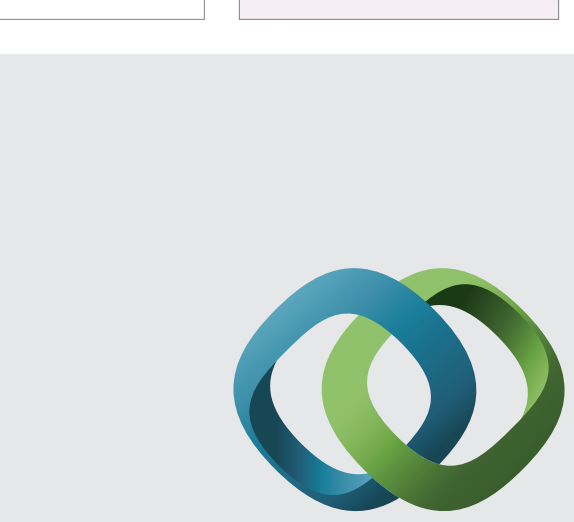

\section{Hindawi}

Submit your manuscripts at

http://www.hindawi.com
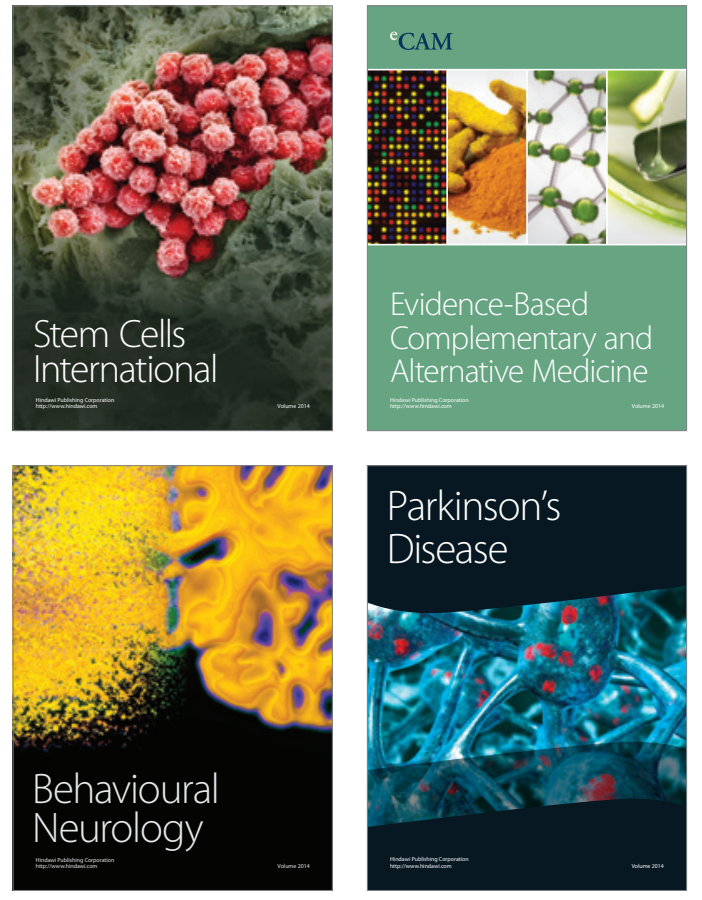
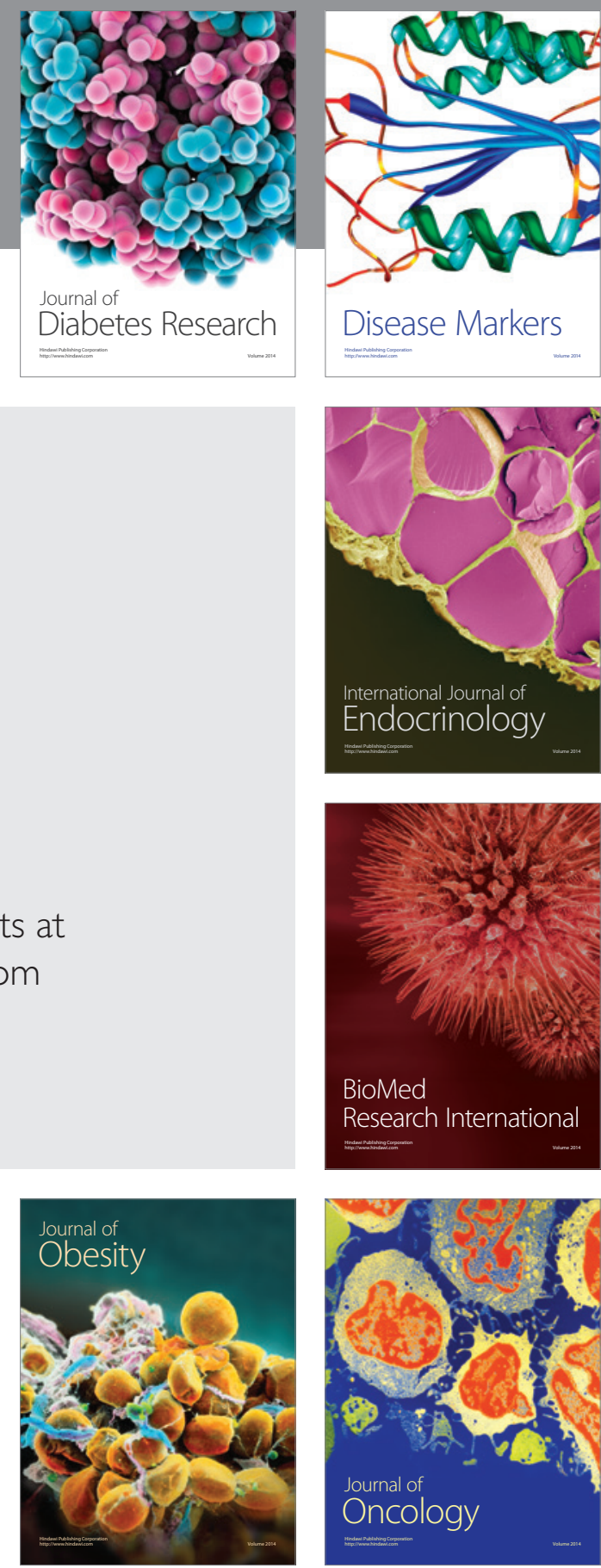

Disease Markers
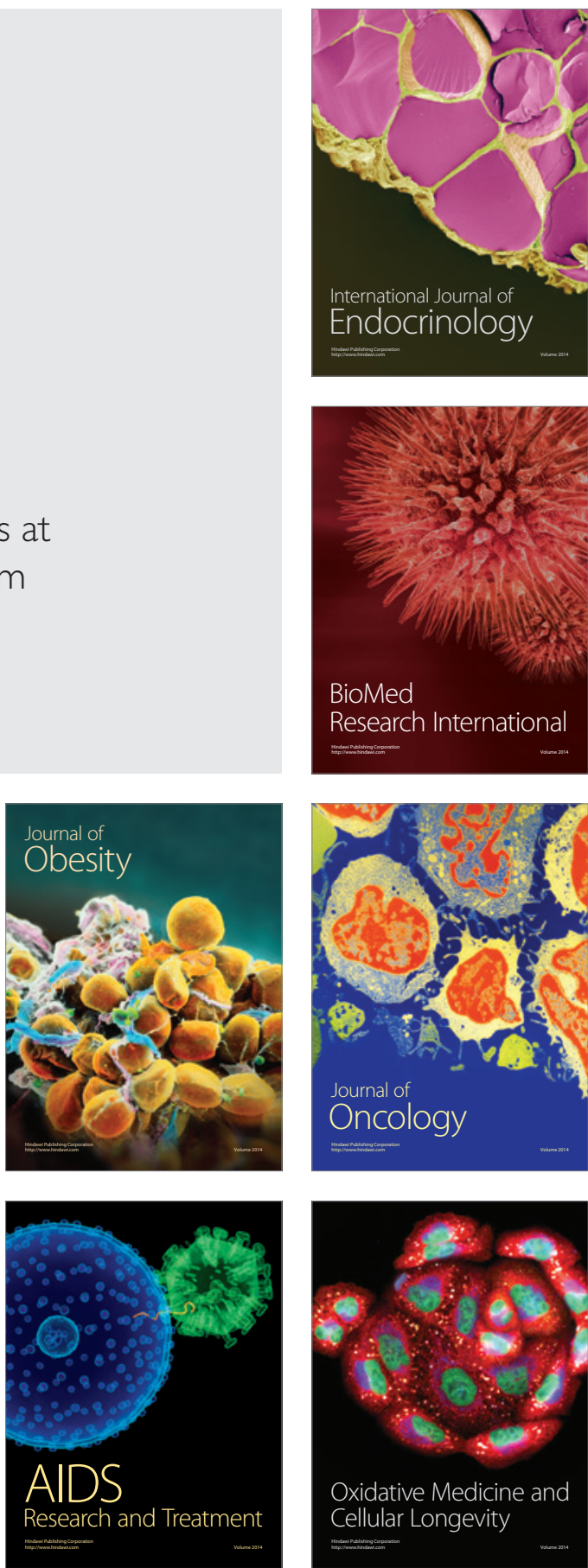